Euskal ikerketen aldizkaria | Revue d'études basques |

Revista de estudios vascos | Basque studies review

2 | 1997

Numéro II

Wascones in plana descendunt... Civitas Lapurdum...

\title{
Renée Goulard
}

\section{OpenEdition}

Journals

Édition électronique

URL : http://journals.openedition.org/lapurdum/1820

DOI : 10.4000/lapurdum.1820

ISSN : 1965-0655

Éditeur

IKER

Édition imprimée

Date de publication : 1 octobre 1997

Pagination : 257-281

ISBN : 2-84127-142-0

ISSN : $1273-3830$

Référence électronique

Renée Goulard, «Wascones in plana descendunt... Civitas Lapurdum... », Lapurdum [En ligne], 2 | 1997, mis en ligne le 01 septembre 2010, consulté le 01 février 2020. URL : http://journals.openedition.org/ lapurdum/1820 ; DOI : 10.4000/lapurdum.1820 


\section{WASCONES IN PLANA DESCENDUNT... CIVITAS LAPURDUM...}

Que l'on veuille bien pardonner un tel titre pour cet article : ce sont les motsmêmes qui mirent le feu à une Histoire, celle de la Wasconia devenue Gascogne dans le royaume franc. Ils sont extraits des Dix livres d'Histoires de Grégoire de Tours!. Entre la sainteté de l'auteur et la critique cinglante des historiens, on donna finalement tort aux intéressés eux-mêmes, nécessairement exclus de toute entreprise historique digne de ce nom, et rangés de façon perremptoire parmi les troublions ${ }^{2}$.

Une fois encore, et sans crainte, penchons-nous sur cette Histoire et relisons ces textes ${ }^{3}$.

En dehors du temps indiqué, celui de la fin du VIe siècle, des guides sont donnés. C'est d'abord la première mention connue des Wascones sur le territoire des Francs, d'autant importante que ces Wascones sont ensuite devenus peuple éponyme d'une région des Gaules. Cette mention est suivie, dans l'œuvre de Grégoire de Tours mais sans indication d'un quelconque rapport entre les deux faits, de la transcription d'un texte dont Grégoire fut sinon l'auteur du moins le conseiller, celui du pacte d'Andelot conclu le 28 Novembre 587, document qui cite Lapurdum parmi les civitates des Gaules.

\section{La fin du VI' siècle marque-t-elle le point de départ d'une Histoire?}

Le texte de Grégoire de Tours conceme les Pyrénées et la province ecclésiastique des Neuf Peuples bordière de la chaîne, province politiquement découpée, morcelée selon des clivages variables lors des partages royaux puisque les rois francs sont le plus souvent multiples. Elle dépend de diverses capitales politiques, résidences de ses rois, au nord de la Loire. On pourrait suivre, mais ce serait ici inutile, le devenir de chaque diocèse au gré des conciles qui reflètent les partages et repérer d'une autre manière cités et régions selon les actions des divers rois. On en retiendra surtout que la province des Neuf Peuples ne forme que rarement un tout, et n'est jamais le centre d'un royaume.

Entrée en théorie depuis 507 dans le territoire franc, cette province a fait auparavant partie de façon très dynamique du royaume goth des Balthes. La bataille de Vouillé n'a cependant mis fin ni à la royauté gothique, ni aux espérances des Goths. Tant que vécut Amalaric, le dernier descendant mâle des rois balthes, les tentatives de restauration sont manifestes". Ensuite, les rois francs qui se veulent les héritiers des Goths, n'ont cessé d'intervenir en Espagne, suscitant lors de leurs éventuelles défaites les espérances gothiques. Mais il y a plus. Les Goths de la province des Neuf Peuples $n$ 'ont pas tous quitté les Gaules devenues franques. Le concile d'Orléans de 51 leur 
faisait immédiatement une offre de résidence, à condition toutefois de se convertir, et cette offre englobait les prêtres goths hérétiques eux-mêmes qui pourraient demeurer en un sacerdoce ${ }^{\sigma}$. Dans des régions mieux pourvues de textes que la province des Neuf Peuples, en Auvergne ou à Rodez par exemples, on voit que les Goths sont demeurés nombreux et savent manifester leur présence jusqu'en cette fin de Vle siècle'. Les rois francs sont de leur côté désireux d'apparaître comme héritiers des Balthes. Ils nouent avec les Goths d'Espagne des alliances matrimoniales aux succès divers : Brunehild, Galeswinth quittent Tolede pour la Francia, Clotilde, Ingonde, et Rigonde -qui fut interceptée à Toulouse- épousent des rois goths. Le pays des Neuf Peuples vit au milieu des remous de la politique générale, aux limites des deux domaines, goth et franc, mais surtout, depuis toujours, il vit à l'heure de la montagne pyrénéenne. Or les Pyrénées bougent en cette fin de siècle.

Au sens propre du terme d'abord : dans les années 580 un effroyable tremblement de terre secoua les Pyrénées et fit jaillir de toutes parts d'énormes blocs de rochers qui roulèrent jusqu'au fond des vallées. La peste s'en mêla, les malheureux refluaient de partout. L'évêque Amélius de Bigorre partit jusqu'à Paris demander des secours, suivi par son domestique qui se faisait passer pour guérisseur et transportait reliques et amulettes. Quant aux troubles politiques, ils entraînent de fréquentes ambassades de part et d'autre des Pyrénées dont les cols furent animés, plusieurs fois par an, de nombreux cortèges de clercs et de laïcs. On apprenait aussi que l'évêque Amélius de $\mathrm{Bi}$ gorre servait en fait d'intermédiaire entre les envoyés de la reine franque Frédégonde et le roi goth Leovigild, plus arien que jamais pour complaire à la redoutable reine Goswinth. La révolte du "prétendant "Gondovald avait trouvé ses plus puissants appuis en Comminges". Les Pyrénées étaient au coeur de l'Histoire. Dans la guerre inhumaine qui opposait en Espagne le roi Leovigild et son fils ainé Herménégild, Childebert, sa mère Brunehild et son oncle Gontran criaient vengeance pour le martyre de la princesse Ingonde mais revendiquaient aussi, vis à vis du roi franc Chilpéric, les terres béarnaises et bigourdanes comme dotation et "morgengabe" de la soeur de Brunehild. Les Pyrénées étaient un champ d'action guerrière et politique des plus emmêlés. Grégoire de Tours, fidèle du roi Gontran, ne pouvait que se lamenter jetant sur les actions des laics de toutes sortes, un voile horrifié. Il est au courant de la dernière nouvelle en provenance du Sud : la montagne vient de déverser chez les Neuf Peuples un flot de montagnards. Il les nomme Wascones.

Sa perception des Wascones ne pouvait échapper à la couleur générale du tableau. Grégoire a assisté à leur entrée dans l'histoire des Gaules, car c'est après ce momentlà que l'on commença à parler non seulement de Wascones mais de Wasconia en territoire franc. Rien ne le laissait prévoir. "Les Wascones, jaillissant véritablement des montagnes descendent dans la plaine. Ils vident vignes et champs cultivés de leur population, mettent le feu aux maisons, enlèvent beaucoup de prisonniers avec les troupeaux" . La descente rapide, le vol et le pillage rondement menés, ne laissent aucun doute : les Wascones entrevus sont repartis. Les maisons brûlées, les vignes ravagées. les troupeaux emmenés, seraient-ils un cliché selon l'auteur qui décrit un coup de main, comme il y en a déjà eu, comme il y en aura d'autres? On peut se demander si, comme en bien d'autres passages de son cuvre et notamment l'anecdote célèbre du vase de Soissons, sa vision des choses n'est pas noircie. Cet auteur aime les images fortes, il sait faire frissonner son lecteur et ne manque jamais une occasion de dénoncer les violences des hommes. Ce n'est pas l'ignorance qui est en cause, car il connaît les Pyrénées. En 579, il a accompagné la princesse Ingonde et a lui-même célébré son mariage à Tolède avec Herménégild, il a donc traversé la montagne et a vu les Wascones dont il parle ${ }^{10}$. 
Dans une anecdote peut-être stéréotypée, Grégoire n'en souligne pas moins le fait que le duc Austrovald, envoyé par le roi Gontran s'est révélé, à plusieurs reprises, inefficace face aux Wascones. Son armée était peut être trop lourde à mettre en mouvement et peu libre de ses zones d'action. Le roi Childebert jugeait de son côté l'instant propice pour mettre son duc Ennodius à la retraite et dégamir les places d'Aire et de Lescar. Trois rois mal installés se partagent cette région aux années 585/587 : un enfant de trois ans et sa coléreuse mère (Clotaire II et Frédégonde), un roi indécis attentif aux douleurs maternelles (Childebert et Brunehild) et le vieil oncle Gontran qui pense encore être le plus fort. Les pouvoirs de Gontran, roi de Grégoire, sont plus que jamais incertains dans le Sud où bien des forces s'affrontent. Avec qui sont les Wascones? Quel est le point d'impact de leur action? Sont-ils favorables, comme Amélius de Bigorre et la dame Leuba, épouse du duc Bladaste, au parti neustrien et comme tels présentés comme des ennemis par Grégoire ? Ce texte ne répond pas et il n'est pas possible d'y trouver mention d'une séquelle de la guerre de Gondovald sans dépasser son strict enseignement. Il prend sa place, parcequ'il contient la première mention des Wascones, dans une histoire de longue haleine, mais il ne dit pas tout ${ }^{11}$.

Il y a notamment la question du sens à accorder au terme de Wascones employé par Grégoire, auquel une culture latine moins pesante qu'on ne l'a souvent dit (il reconnaît lui-même que son latin est rustique) n'enlève pas une bonne connaissance de son temps. Les Wascones posent problème ${ }^{12}$. Ils sont présentés par Grégoire comme des montagnards, c'est tout ce que l'on en peut dire au VI' siècle.

Pour tenter de mieux connaître ces peuples qui apparaissent pour la première fois à la fin du VIe siècle il n y a guère d'autre issue pour l' historien qui n'est pas linguiste, que d'établir un rapprochement avec des peuples au nom voisin. Est-il possible de rapprocher les Wascones des Vascones connus au sud des Pyrénées depuis le ler siècle avant notre ère et qui continuent à être mentionnés dans les textes d'Espagne ? Plusieurs indices relatifs aux similitudes des civilisations pré-romaines sur les deux flancs de la montagne pyrénéenne invitent l'historien et l'archéologue à un tel rapprochement. Un regard du côté des Vascones peut donc se révéler utile, sans rechercher toutefois lexhaustivité des textes et en remarquant que les fouilles archéologiques sur le territoire des plus anciens Vascones repérés sont toujours à faire ${ }^{13}$.

\section{Les Vascones et leur saltus}

Les plus anciennes mentions des géographes et les premières actions guerrières de ces peuples commencent au Ier siècle avant J.-C. Le géographe Polybe ( $\dagger 126$ av. J.-C.) ne les nomme pas mais avoue sa méconnaissance de ces régions où il n'a entendu parler que de Cantabres, Varduli et Vaccei. Le premier à les nommer est Strabon qui achève sa propre "Géographie" en 17 de notre ère mais utilise un ouvrage plus ancien aujourd'hui perdu, (celui de Poséidonios d'A pamée qui mourut en 59 av. J.-C.). Il donne les premières mais décisives indications : Les Ouaskoonoö̈ sont un peuple et ils habitent un territoire défini. Ils ont un genre de vie montagnard, au pied des Pyrénées et sont installés à Oyarzun, Pampelune, Calagurris trois lieux repères que désormais plus personne n'oubliera ${ }^{12}$. Calagurris surtout qui colore immédiatement la définition du Ouaskoonoon ethnos.

Salluste ( $\div 28$ av. J.-C.) dont l'œuvre sur la guerre de Sertorius dans laquelle Galagurris s'illustra est perdue, a donné le ton, et il inspira Tite-Live († 17) dans son livre 91 qui précisément n'existe plus qu'à l'état de lambeaux de palimpseste, mais il n'importe : on apprend que les Calagurritani fibularenses, qui sont des Vascones, ont 
poursuivi en 72 av. J.-C. la lutte contre Pompée, après l'assassinat de Sertorius et qu'ils subirent de la part du général pompéien Afranius un long siège qui était censé les affamer. Lorsque la ville capitula, il n'y avait que les corps des guerriers et le silence. Où étaient les non-combattants ? Le général romain imagina que les guerriers les avaient... mangés avant de mourir..." et le reste en salaison !" disait-on dans les salons de Rome comme pour dire "et le reste à l'avenant !" "César livre un peu plus tard le secret de ces forteresses et les fouilles archéologiques de Sos (France) où la fortification a été construite par des anciens des guerres de Sertorius, le confirment : on pouvait quitter ces forteresses sans être vu, par des galeries souterraines débouchant assez loin ${ }^{16}$. Cette triste anecdote devait être véhiculée pendant des siècles, jusqu'à l'écrivain Orose $(\dagger 417)$, au seuil des temps gothiques ${ }^{17}$. Nous $n$ 'y reviendrons pas. Le legs du ler siècle av. J.-C. est des plus importants puisque le peuple et son territoire sont nettement indiqués par Poséidonios/Strabon, dans le piémont pyrénéen, et plus particulièrement à l'ouest de Huesca. Rien dans la définition du territoire ne permet alors de l'identifier à un saltus, c'est-à-dire à une zone boisée, sauvage, inhospitalière.

Au Itr siècle de notre ère deux mentions intéressantes sont données par Tacite puis par Pline le Jeune. Tacite, dans un récit de l'année 69, présente les troupes auxiliaires de Vascones se portant au secours des Romains en difficulté sur le Rhin. La cavalerie romaine a été culbutée, les enseignes gisent à terre, la bataille est perdue. Les fantassins auxiliaires Vascones arrivent alors sur le dos des assaillants bataves avec tant de fougue que l'on crût à l'arrivée de l'armée complète de Mayence. Les Romains reprirent courage et l'avantage dans le combat. Les Vascones sont de redoutables guerriers qui connaissent non seulement la poliorcétique, mais savent combattre en fantassins. Leur profil se précise comme celui de guerriers ${ }^{18}$. Avec Pline, nous entrons dans la longue série des nomenclatures de peuples, pâture privilégiée des historiens qui, bon an mal an, font naître des dizaines de mises au point et rectifications. Les Vascones sont comme tels absents des répertoires de peuples présentés par Pline qui indique cependant, au sein du conventus de Saragosse (assemblée politique obligatoire) les noms de villes déjà connus. On y retrouve les malheureux Calagurritani fibularenses chargés du terrible statut de stipendiaires. En revanche une formule destinée à un long avenir fait son apparition dans l'oeuvre de Pline : près des Pyrénées et de l'Océan se trouve le sultus Vasconum, seule apparition du peuple et de l'un de ses territoires dans une œuvre somme toute décevante ${ }^{19}$. Pline n'a pas été attentif aux genres de vie, mais à l'organisation politique romaine. Les Romains ont dans l'ensemble moins bien regardé les Vascones que les Grecs qui ont bien su rendre leur nom : Ouaskoonooï.

Au second siecle le géographe Ptolémée présente, comme Strabon et Poséidonios avant lui, deux passages distincts relatifs aux Ouaskoonooi. C'est d'abord le promontoire des Ouaskoonooï et la ville (polis) d'Oiasso (Oyarzun), puis, à l'intérieur, les noms de 15 places fortes des Ouaskoonooï où se retrouvent certains noms indiqués par Pline comme membres du conventus de Saragosse. La localisation du peuple est un peu plus vaste qu'au temps de Poseidonios/Strabon et l'on peut se demander si ce peuple n'est pas reconnu comme plus important que ses voisins ${ }^{2 n}$. Ensuite l'Histoire et la Géographie s"intéressent à des thèmes nouveaux et les Vascones ne reparaîtont guère dans de grands ouvrages de l'Antiquité. La correspondance savante entre Ausone et Paulin de Nole à la fin du IV' siècle est toutefois intéressante. La contrée des Vascones ne peut être qu 'un saltus, terre inhospitalière, bois touffus, vallées sombres, et ce peuple n'est qu' un "hôte inhumain", "sauvage comme les bêtes" (ce qui est l"anti-civilisation romaine), "barbare" (ce qui est l'anti-langue romaine). Ausone n"aime que la romanité et les méprise en bloc, Paulin les aime en charité chrétienne. Dialogue 
de sourds mais qui surtout passe loin des intéréssés ${ }^{21}$. Au fond, en cette fin des temps romains, les Vascones ont quelque chance d'être confondus avec les Germains, comme eux hôtes des bois et de la nature, comme eux peu assurés dans la langue latine, comme eux chargés de chants qui ne concernent que leur peuple, comme eux qualifiés "barbares" ". Le face à face avec les Goths puis avec les Francs pouvait commencer.

Le $V^{\circ}$ siècle mit les Vascones au contact des populations réputées germaniques. Ils connaissaient depuis longtemps les fédérés francs cantonnés dans les ports pyrénéens par les généraux des armées romaines, soldats de Rome et de l'empereur, et qui n'avaient que fort peu de ressemblance avec les "Barbares" qu'ils découvrirent en 409. Alains dominateurs, Suèves diplomates, essaim de Vandales dont la réputation était déjà solide, s'entretuent et pillent les contrées traversées franchissant en bourrasque le col de Roncevaux et se répandant immédiatement jusqu'au fond de la Galice et de la Bétique avant que les Vandales ne traversent la mer et ne gagnent I'Afrique, mais non sans retours toujours imprévus. On sait que, la même année, une armée a été levée dans les Pyrénées par les partisans de l'empereur Honorius pour s'opposer non point à ces hordes mais à un usurpateur du trône impérial ${ }^{23}$. Rome n'est plus intéressée que par la compétition pour la magistrature impériale. Les montagnards, dans la bonne tradition romaine, forment encore des contingents guerriers disponibles, mais bientôt une autre attitude commence à les caractériser. Elle est plus proche des comportements barbares entrevus pour les Germains, en tous cas elle tient compte de leur présence.

En 413, les Goths font leur apparition en Espagne et dans les Gaules. En 418 ils sont installés à la demande de l'assemblée des Sept Provinces dans les régions de la Garonne, du littoral atlantique et dans la province des Neuf Peuples. Un pouvoir guerrier se met en place, qui concerne les Gaules du sud mais va se trouver devant la nécessité d'intervenir en Tarraconnaise que ne maîtrisent ni les Romains ni les Suèves et où les Goths prennent progressivement pied. Le péril extérieur mais plus encore le soulèvement appelé "bagaude" sévit de part et d'autre des Pyrénées, comme ailleurs. En 443 à Aracelli (Araquil), près de Pampelune et sur la route Astorga-Bordeaux que chacun tente de dominer, la bagaude fait rage et sa répression se veut lourde. En février 449 , le jeune roi suève de Galice, Recharius, vient d'obtenir comme épouse la fille du roi balthe Théodoric Ier et se prépare au voyage de Gaule : il fait ravager les Vasconias à l'aller et pille Saragosse au retour, au mois de Juillet. Le roi balthe Frédéric, intervient lui-même en Tarraconnaise en 454, toujours contre les bagaudes, et le roi Euric envoie son comte Gauteric en campagne dans la région de Pampelune aux années $48 \mathrm{O}^{34}$. Chacune de ces interventions oblige les Goths devenus maîtres de ces régions à dégarnir leurs défenses dans les Gaules, ce qui est immédiatement exploité par les Francs, mais la progression gothique dans les Espagnes est régulière.

Les textes ne laissent aucun doute sur la perception que les Goths eurent des Vascones. Ils ne sont plus les guerriers en puissance qu'ils étaient dans le paysage politique romain, soutiens d'un parti ou de l'autre ou membres de la garde impériale, mais la géographie et l'histoire romaines sont largement oubliées. Les Goths sont euxmêmes avant tout des guerriers, et la seule armée repérable dans leur royaume est l'armée gothique, dont le recrutement est ouvert il est vrai. On a beaucoup dit que les Vascones se sont trouvés gênés dans leur expansion par la mise en place de royaumes guerriers. Mais personne n'a su dire pourquoi les Vascones étaient en expansion, aussi on a inventé toutes sortes d'explications, de la férocité naturelle d'un peuple à la désertification des montagnes, sans oublier la lutte pour un genre de vie (qui avait été 
beaucoup plus menacé par les Romains qu'il ne l'était par les Goths). Ils héritent bientôt seuls du qualificatif de "Barbares" tandis que les autres peuples autrefois réputés "barbares" constituent des royaumes.

Les remous qui suivirent la bataille de Vouille (507) et les compétitions gothiques en Espagne n'ont pas trouvé d'historien pour relater les possibles raids des Vascones et leurs éventuelles répressions au début du $\mathrm{VI}^{\circ}$ siècle. Le combat se situe sur un autre niveau et Pampelune est devenue un enjeu dans les rivalités franco-gothiques et sera comme telle assiégée en 541 pendant cinquante jours. Peut-être y eut-il un temps d'arrêt dans la question des Vasconias d'Espagne ?Il serait alors bon de se demander pourquoi.

Fuyant l" "Histoire catastrophe" qui est une véritable école selon laquelle les Vascones s'agitent car telle est leur nature, le fruit de leur perfidie, nous remarquons qu'ils ne sont pas les seuls peuples à s'agiter, que la Bétique aux larges domaines bovins, que d'autres régions montagneuses pourvoyeuses de troupeaux et notamment de chevaux font de même, sont l'objet de représailles et reçoivent de puissants encadrements gothiques. En fait les Goths s'installent, progressivement et de façon sporadique dans les régions d'Espagne les plus intéressantes pour eux. Ils dressent et redressent dans les zones qu'ils occupent de façon préférentielle, des fortifications qu'ils munissent de puissantes gamisons (on vit les murs d'Italica resurgir de leurs fondations pour impressionner les habitants de Séville). Le pays des Vascones et plus particulièrement celui des cols occidentaux qui mettent en rapport les Gaules, premier royaume goth, et les Espagnes dont la conquête commença dès les premiers temps des Gaules gothiques, reçurent de forts contingents de Goths. Il fallut souvent déloger les occupants qui bien évidemment tentèrent de s'opposer au mouverment et prirent les armes. Le pays des Vascones, ses forêts et ses pâturages n'a pas été vu comme un saltus par les Goths dont sait qu'ils étaient plus attentifs à ces paysages-là qu'aux moissons. Le saltus est une invention de Pline qui, après lui, fit autorité auprès de toute personne se voulant cultivée et ce saltus traînait dans son sillage le mépris pour ses habitants. Les Goths donnent un autre reflet du pays des Vascones. A la fin du VI ${ }^{\circ}$ siècle, Venance Fortunat le considérait comme une richesse (ops).

Les combats ne reprirent qu'à la fin du Vle siècle, temps où les derniers contingents de Goths des Gaules, ont perdu tout espoir de voir renaitre la puissance balthe (vraisemblablement représentée jusque là par une femme, car les femmes transmettent les droits à la couronne balthe). Certains demeurent définitivement dans les Gaules franques. D'autres passent dans les Espagnes et viennent de nouveau prendre place dans les mêmes régions qu' auparavant. Les Goths ne sont pas de pauvres paysans mais une caste aristocratique qui demande de vastes espaces et cela rend leur installation difficile. Bientôt, après la stabilisation des contingents gothiques, les luttes entre factions pour l'accession à une royauté élective font de nouveau entrer les Vascones dans les querelles de la politique royale, mener insurrections et révoltes caractérisées, parfois-même sous la conduite d'un Goth ".

Les débuts de leur histoire avaient trouvé les Vascones actifs dans la continentale et montagneuse Calagurris. Leurs résidences espagnoles étaient multiples à la fin du $V^{c}$ siècle et Hydace avait bien employé le pluriel pour désigner leurs pays au sud des Pyrénées. Aux dernières décennies du VI' siècle les Wascones sont peuples de la montagne, mais ils sont aussi peuples de l'Océan. Dans cettedémarche, ils rencontrent encore les Goths mais aussi les Francs. 


\section{La "civitas Lapurdum"}

Grégoire de Tours reproduit le texte du pacte d'Andelot conclu le 28 Novembre 587 entre les rois Gontran et Childebert. Il fait mention de la civitas de Labourd dans un passage du pacte où sont repris les termes d'un accord plus ancien, celui de 567 , lequel s'appuyait déjà sur la longue série des partages francs antérieurs. On sait que Labourd (Bayonne et son territoire) reçut à la fin du IIIe siècle une organisation castrale et servit de cantonnement à une cohorte dite cohorte novempopulanienne. L'empire romain était au III $^{e}$ siècle finissant bardé de castra sur tous les fleuves, dans tous les ports, sur tous les itinéraires, et leur défense confiée aux fédérés ou aux autochtones. Labourd a fait partie d'une telle organisation. Labourd était un castrum.

A la fin du VI' siècle, le pacte d'Andelot met l'accent sur de nouveaux renseignements. Labourd n'est pas appelée castrum mais civitas. Comme il vient d'être dit, l'appellation civitas Lapurdum que l'on trouve dans le texte d'Andelot n'est pas une création verbale de la fin du VI' siècle, mais bien plutôt de son début puisqu'il y a eu reprise de documents anciens. Dès lors, ce n'est plus en territoire franc qu'il faut chercher le sens de cette civitas mais en territoire et langage gothiques au sein desquels il put naître, entre 418 et 507 d'abord et au plus juste, temps du royaume balthe. La phrase qui contient l'expression est prononcée par le roi Childebert : "De la même manière, le seigneur roi Childebert revendique à partir de ce jour comme étant en sa puissance les cités de Meaux, Senlis aux deux tiers, Tours, Poitiers, Avranches, Aire, Couserans, Labourd et Albi, ainsi que leurs territoires". On ne saurait pourtant s'arrêter à une traduction littérale, "la cité de Labourd ", qui ferait penser à l'existence d'un évêché de Labourd, sens habituel du terme "cite", bien que la suite des temps ait incontestablement conféré à Labourd le titre de cité épiscopale ${ }^{26}$. Il faut replacer l'usage du terme en son temps, dans son milieu historique et notamment dans son entourage politique religieux et militaire.

Le sud des Gaules connaît alors une heure qui semble décisive de mise en place des Francs et des Goths. A l'extrémité orientale nord des régions subpyrénéennes. la Septimanie est restée politiquement gothique, elle est partie constitutive du royaume goth. En revanche, au sud-ouest des Pyrénées franques, il existe comme une contrepartie à l'avancée gothique dans les Gaules, une avancée franque au Nord-ouest du monde goth. La Cantabrie littorale a en effet constitué un commandement franc pendant plusieurs années du VI' siècle et au début du VII' siècle. Ce commandement fut un temps tenu par un duc appelé Francio. Son étendue allait vers l'Ouest jusqu aux confins de la Galice et rejoignait à l'Est la zone pyrénéenne ${ }^{27}$. Lorsqu'en 574 le roi goth Léovigild souhaita établir sa puissance en Cantabrie, il pilla Amaya, mais ne put s'installer ni progresser jusqu' aux rivages pour surveiller "les envahisseurs" possibles de son royaume, Cantabres sans doute, mais aussi Francs du duché littoral. Ensuite il mit en place, après sa campagne contre les Vascones en 581, un "duché de Cantabrie" $:$. La position franque était solidement établie et il y eut vraisemblablement des tentatives de progression vers la Galice puisqu'en 583, tandis que Léovigild mettait en son pouvoir le demier bastion du royaume galicien suève, des navires francs croisaient le long des côtes de Galice ${ }^{29}$. La présence franque sur le littoral entre Galice et Pyrénées a gêné le roi Léovigild mais elle a obtenu l’aval des autorités impériales byzantines, catholiques, ennemies du roi goth hérétique, non seulement en Bétique où les positions sont bien connues, mais en Cantabrie où la reconquête ultérieure par le roi Sisebut est présentée comme un arrachement des places-fortes maritimes au pouvoir impérial. L'existence de ce duché franc sur le łittoral cantabre revêt pour Labourd une certaine importance. 
L'implantation franque, malchanceuse en Septimanie, est réussie en "Cantabrie" au cours du VI" siècle où elle se fit selon la forme apprise des Goths, celle du ducatus (commandement ducal), bien adapté aux besoins militaires. Les Francs n'ont rien rejeté des institutions gothiques qui pouvaient les servir. Le commandement ducal dont ils font usage, devenu banal en cette fin de VI' siècle, est lui-même un legs gothique. Un siècle plus tôt, les lois d'Euric y faisaient allusion mais la loi est moins probante que l'evénement : or, en 498, lors d'une de ses poussées à l'intérieur du royaume goth des Gaules, le roi franc Clovis enlevait Suatri, duc goth de Bordeaux ${ }^{30}$. L'ancien "Tractus Armoricanus" romain partait du nord des Gaules et s'arrêtait à la Gironde. Il a été complété au temps des Balthes par un commandement dont le ressort comprenait d'abord la cité de Bordeaux et celle des Bö̈ens qui s'allonge vers le sud à la rencontre des terres labourdines. Ce "duche" (territoire où s'exerce le commandement d'un duc) de Bordeaux est maintenu dans l'organisation franque soucieuse de la défense des rivages de l'Océan. Mais les Francs sont beaucoup moins bien placés pour en assurer le bon fonctionnement que ne l'avaient été les Balthes goths qui n'avaient qu'un seul roi, ne partageaient pas le royaume, et dont l'autorite était d'abord de justice guerrière. Au sud comme au nord de Labourd, on relève deux zones de commandement militaire, cependant sur la vaste étendue littorale ainsi organisée, de véritables problèmes se posent.

Les Francs découpent le territoire qui porte leur nom, à chaque décès royal. Dans la province des Neuf Peuples ils ont hérité d'une situation complexe puisque le "duché" de Bordeaux était installé sur deux provinces différentes : les Boïens comme les peupies plus méridionaux avaient appartenu aux Neuf Peuples tandis que Bordeaux était métropole d'une autre province, celle d'Aquitaine Seconde. Les Francs compliquèrent plus encore la mosaïque politique de la région. Les circonscriptions de Bordeaux et de Dax, diocèse qui comprend Labourd, sont généralement dans le lot du roi qui tient la Neustrie, mais il n'en est pas de même pour les autres diocèses. L'attache neustrienne de Bordeaux et de Dax est bien connue au temps de Charibert Ier ( $\div$ 567). Son successeur neustrien, Chilpéric ( $\dagger$ 584), posséda assurément Bordeaux, Dax, Aire, mais aussi Béarn, Bigorre, Comminges, ces listes n’étant pas limitatives. Mais en 585, on voit que "le bon roi Gontran" de Bourgogne gère le tout et qu'en 590 encore, il fait nommer l'évêque de Bordeaux. En 587, à Andelot, une mise au point est obtenue par Childebert, (Austrasie), qui revendique précisément Labourd (mais sans doute pas la totalité de Dax) ainsi qu'Aire, tandis que Gontran reste maître de Bordeaux. Il semblerait donc que la bonne marche du duché de Bordeaux soit soumise aux ententes entre les rois, le sort de Labourd sujet à variations. A travers l'action de Brunehild, mère gothe de Childebert, on perçoit la politique austrasienne de main-mise sur la province des Neuf Peuples, politique soutenue un temps par le roi Gontran, et que combat avec achamement la reine veuve et rusée des Neustriens, Frédégonde ${ }^{31}$.

Il ne faut donc pas s'étonner de voir Labourd séparé du reste du diocèse de Dax, et placé sous la houlette du duché de Bordeaux sans égard à ce qu'il advient du diocèse de Dax à la fin du VI' siècle. C'est l'époque où l'évêque de Poitiers, Venance Fortunat, qui connaissait bien les relations franco-gothiques et les problèmes pyrénéens puisqu'il avait fait en 579 le voyage d'outre-mont, souhaitait que son ami Galactoire soit décoré du tire de duc de Bordeaux ${ }^{32}$. Le point le plus important de ce texte est qu'il définit le ressort d'action du duc de Bordeaux : les Vascones et les Cantabres sont soumis à sa surveillance, ce qui ne peut se faire en excluant Labourd qui est sur la trajectoire stratégique bordelaise. "Duche" de Bordeaux incluant la surveillance des mondes plus méridionaux, "duché" franc de Cantabrie, impontance de Labourd, constituent des 
jalons précis de protection franque. Il existe donc à la fin du VI ${ }^{\mathrm{c}}$ siècle, un vaste commandement militaire appuyé sur le littoral et qui relève de la maîtrise des Francs de Bordeaux. Mais quel est le rôle de Labourd au milieu de ce vaste commandement militaire? Que signifie son titre de civitas?

Grégoire de Tours parle de Labourd comme d'une civitas en 587, or, en 581 un roi goth d'Espagne, Léovigild, utilise le même terme dans un sens bien précis. Il vient de livrer de lourds combats contre les Vascones et, pour assurer le résultat de sa victoire, il fonde la civitas victoriaca, c'est-à-dire que, selon son habitude, il restaure une forteresse antique, ici celle qui porte le nom romain de Véleia, pour surveiller la route... de Bordeaux. Ce site, Iruña, dominant de 70 mètres de hauteur la rivière Zadorra, est une redoute mais ne fut ni ne sera un évêché. Il la nomme cependant "civitas" ce qui laisse entendre que, pour ce roi, une civitas est une place-forte ${ }^{3 n}$. Les exemples abondent dans le royaume goth de ces cités qui sont des forteresses dotées d'un territoire de surveillance et de commandement. Il est bien évident que ce qui intéresse Léovigild, comme jadis Euric dans les Gaules, ce ne sont pas seulement les cités-résidences des évêques catholiques mais les centres de son administration, de sa justice, de son armée, lesquels se trouvent soit dans les villes soit dans les gamisons castrales qui ont même statut que les cites ${ }^{34}$. Depuis longtemps sans doute, et parce qu'Euric avait eu une politique de réorganisation du territoire plus favorable aux comtes et aux ducs qu' aux évêques - qu 'il oublia de remplacer ou qu'il incarcéra -, les ternitoires des forteresses bien restaurées sont devenus l'équivalent des civitates dans le domaine politique.

Labourd, revendiqué dans le pacte d'Andelot par le roi Childebert comme lui revenant en vertu des partages précédents, est une grosse forteresse munie, le texte le précise, d'un territoire de commandement qui comprend au moins une partie du diocèse de Dax mais que rien n'oblige à calquer les divisions religieuses et qui peut fort bien s'étendre beaucoup plus largement, notamment vers le Sud. Le noyau initial du territoire labourdin est formé d'une portion de circonscription épiscopale, ce qui n'est une exception ni chez les Goths ni chez les Francs. Senlis est dans le même texte découpé, et l' on sait qu' au même moment un évêché de Châteaudun est crée sur une partie de celui du Mans remis à deux rois différents et ces faits correspondent à la diversité des situations. Le cas de Labourd est un troisième exemple, lui aussi différent. Le territoire commandé par la civitas de Labourd ne revêt pas nécessairement une définition religieuse, mais il est évident que cette forteresse munie d'un territoire pourra être la première esquisse du futur évêché de Labourd. Or lorsque celui-ci apparaît dans les textes, il déborde largement au sud des Pyrénées, ce qui est le reflet de la circonscription qui a dessiné son assise, qui lui a donné le jour. A la fin du VI siècle, les limites sud-occidentales du territoire franc sont ainsi bien confirmées par plusieurs textes contemporains. Labourd entre dans la politique concertée des rois francs pour la défense des littoraux, et révele la durable empreinte d'une terminologie gothique dans un contexte de défense militaire.

Labourd est alors entre les mains sinon d'un comte du moins d'un personnage ayant des atributions voisines des obligations comtales dans le domaine militaire. C'est un point fort dans la défense contre les peuples des mers attirés par les richesses des royaumes établis et défendus par les forces franques, impériales, suèves puis gothiques. Venance Fortunat rappelle en outre qu'au titre de duc de Bordeaux est dévolue la mission de surveillance des Vascones et des Cantabres ${ }^{35}$.

La frontiere occidentale entre les mondes gothique et franc passe beaucoup plus au Sud et à l'Ouest que celle qu'avaient dessinée les Romains entre Aquitains et Es- 
pagnols. En une époque que les historiens ont tendance à considérer comme celle d'une résurgence des réalités pré-romaines au point que les villes changent de nom, font revivre les vocables pré-romains, où des coutumes en apparence oubliées reprennent vie, où les Armoricains commencent à se vouloir Bretons ou au moins Celtes, il semble qu'une page romaine d'histoire soit tournée. Le VII' siècle va affermir ces tendances.

\section{Naissance de la Wasconia}

Le siècle s'ouvre sur l'apparition de la Wasconia comprise comme un duché du monde franc. Il est possible de laisser de côté à partir de ce moment les événements espagnols qui n'ont plus qu' une incidence indirecte sur les destinees du Sud-Ouest des Gaules. Les agitations de Vascones, avec un $(V)$ initial, continuent à se manifester, sous les divers règnes des Goths d'Espagne, et cela jusqu'à l'arrivée des troupes de Berbères islamisés d'Ifriqiya, en $711^{36}$. Deux textes espagnols sont cependant à mettre à part, l'un indique, précisément en 610, une guerre de Gundemar contre les Wascones, avec $(W)$ comme lettre initiale, l'autre, portant même graphie, désigne les Wascones que combattirent les Goths parmi les guerriers francs en Septimanie en $674^{37}$. Entre temps la Wasconia était née, membre du territoire franc.

Le premier texte franc indiquant la Wasconia comme formant l'axe d'un duché fait référence à une organisation administrative mise en place par Thibert II et Thierry II, tous deux fils du roi Childebert, et conduisant une politique forte sous la houlette de leur grand-mère Brunehild. C'est, en l'année 602, et dans le cadre d'une compétition pour la domination des terres de l'Ouest maritime, comme il apparaît dans les luttes et actions diplomatiques qu'ils conduisirent face à leur cousin Clotaire II. Ils ont en 596 hérité des cités de Bordeaux, Dax, Labourd (pour reprendre la terminologie de leur père) ainsi que de la plus grande part de la province des Neuf Peuples, héritages conjugués de Childebert leur père et de leur grand-oncle Gontran. Il est vrai que des guerres, suivies d'avancées et de replis qui ne sont pas toujours bien localisés - quoiqu'ils ne semblent pas avoir concemé le sud des Gaules - ont pu modifier la situation avant 602 . Cependant, pour cette année 602 , celle où l'on voit la mise en place d'un duc auprès des Wascones, rien ne s'oppose à ce que Bordeaux ait été la résidence ducale, mais ce n'est plus un duché de Bordeaux, c'est un duché des Wascones et c'est ainsi que désormais les ducs intallés en cette région seront nommés, ce qui implique l'appartenance des Wascones à l'aire géopolitique des rois francs :"En 602, Thibert et Thierry dirigent une armée contre les Wascones et, avec l'aide de Dieu les ayant soumis à leur pouvoir, ils en exigent le cens. Ils instituent Genial (ou Gemial ou Gelian) comme duc au-dessus d'eux, et celui-ci les gouvema avec bonheur" ${ }^{38}$. En bons hérjtiers de la tradition austrasienne, Thierry et Thibert sont soucieux de cette région que le règne goth et hérétique de Witteric semble avoir troublée dans ses confins gothiques. Thierry a tenté de négocier avec ce roi une alliance, et il a envoyé des ambassadeurs pour demander la main de la princesse Ermenberge qui devait bien être aussi hérétique que son père. Le mariage touma court et l'année n'était pas écoulée que la princesse était renvoyée à son père, dépouillée de ses trésors, suscitant l'indignation de tout l'Occident "39. Il s'agissait donc de bien structurer le pays des Wascones contre de possibles représailles gothiques. Mais cette raison n'est pas suffisante pour faire changer ce "duché" de nom. Il importe d'abord d'en connaître l'assise afin de savoir si Bordeaux, qui n'est plus référence de nom en fait toujours.partie et si le changement de nom ne vient pas de son éventuelle absence. 
L'étendue du duché n'est indiquée que pour une période postérieure, mais proche de cette première mention relative à son existence, et où il est question de son intégration dans un ensemble plus large, le territoire de Charibert II crée à l'issue du règne de Clotaire II ( $\dagger 18$ octobre 629). Ce roi avait succédé aux deux frères, Thibert et Thierry ( $\dagger 612$ et 613$)$ dans leurs royaumes. Dagobert, fils de Clotaire II, concède de mauvais gré au printemps 630 , quelques terres à son frère pour que celui-ci puisse vivre et surtout pour qu'il ne revendique rien de plus de l'héritage paternel. Il s'agit de plusieurs éléments, mais l'un d'eux, remis selon le droit privé, fait référence à la Wasconia :" tout ce qui s'étend de la Loire au limes de l'Espagne, dans les régions de la Wasconia, à savoir les comtés (ou pays) et les cités (ou châteaux) de la montagne pyrénéenne.... et tout ce qui, au-delà des comtés de Toulouse, Cahors, Agen, Périgueux et Saintes s'étend de là aux monts Pyrénées " ${ }^{40}$. La composition de la Wasconia est alors bien claire : elle comprend les terres des Pyrénées et celles qui sont placées au Sud ou à l'Ouest de comtés et cités qui sont précisément nommés et n'en font pas partie. Ces comtés s'étendent autour de la Garonne. La carte dressée ci-contre montre qu' il s' agit de trois pôles. On trouve d'abord le comté-duché de Bordeaux qui confine au nord les comtés de Saintes et Périgueux. Ensuite viennent les terres novempopulaniennes qui confinent au Nord les comtés de Périgueux, Agen, celui de Cahors au droit de Lectoure, et à l'Est le comté de Toulouse. Enfin, au sud-Ouest, se trouvent les terres de la cité de Labourd qui débordent hors de la province des Neuf peuples, sur un limes, c'est-à-dire une zone où la frontière (termini. fines dans le vocabulaire de ce temps) n'est pas considérée par les Francs comme stabilisée (perte récente du duché cantabre pour la définition en 630).

La Wasconia dessinée dès 602 était un vaste territoire, en partie montagnard, en partie maritime, en partie constitué de ce pays des Neuf Peuples jadis vanté comme un paradis par Salvien. Elle se modifia, sinon dès 610, la campagne de Gundemar contre les Wascones n'ayant peut-être pas été aussi efficace que le dit Isidore de Séville. du moins dès l'envoi par Sisebut du duc Richila en 612, alors que les deux frèresrois francs étaient en désaccord et que Thierry II triomphait de Thibert II dans une seconde bataille de Tolbiac, bien loin des Pyrénées, et que leur cousin Clotaire II devenait de plus en plus puissant. La Cantabrie était perdue, il ne restait au sud des Pyrénées qu un pays composé au moins de ce qui devait par la suite entrer dans le diocèse de Labourd. Bordeaux ne lui donne plus son nom. Les Neuf Peuples en demeurent le coeur, et pourtant le duché ne porte pas leur nom. Il est vrai que la Garonne d'un côté et Labourd ultra-pyrénéen de l'autre indiquent des zones d'intérêt en dehors du territoire novempopulanien. Bordeaux ne sert plus de référence. Ce duché est une marche face au royaume goth, mais les dangers représentés par cette proximité ne furent pas suffisants pour lui donner le nom de duché de Gothie. On le désigna du nom des Wascones, ce qui signifie que c'est là qu iil faut reconnaitre sa référence et qu 'une mise en place est achevée. Une fois encore les guerres des Wascones apparaissent liées à la politique générale et ne sont pas la conséquence d'une sauvagerie naturelle. 
Le premier duché de Wasconia au début du VII' siècle

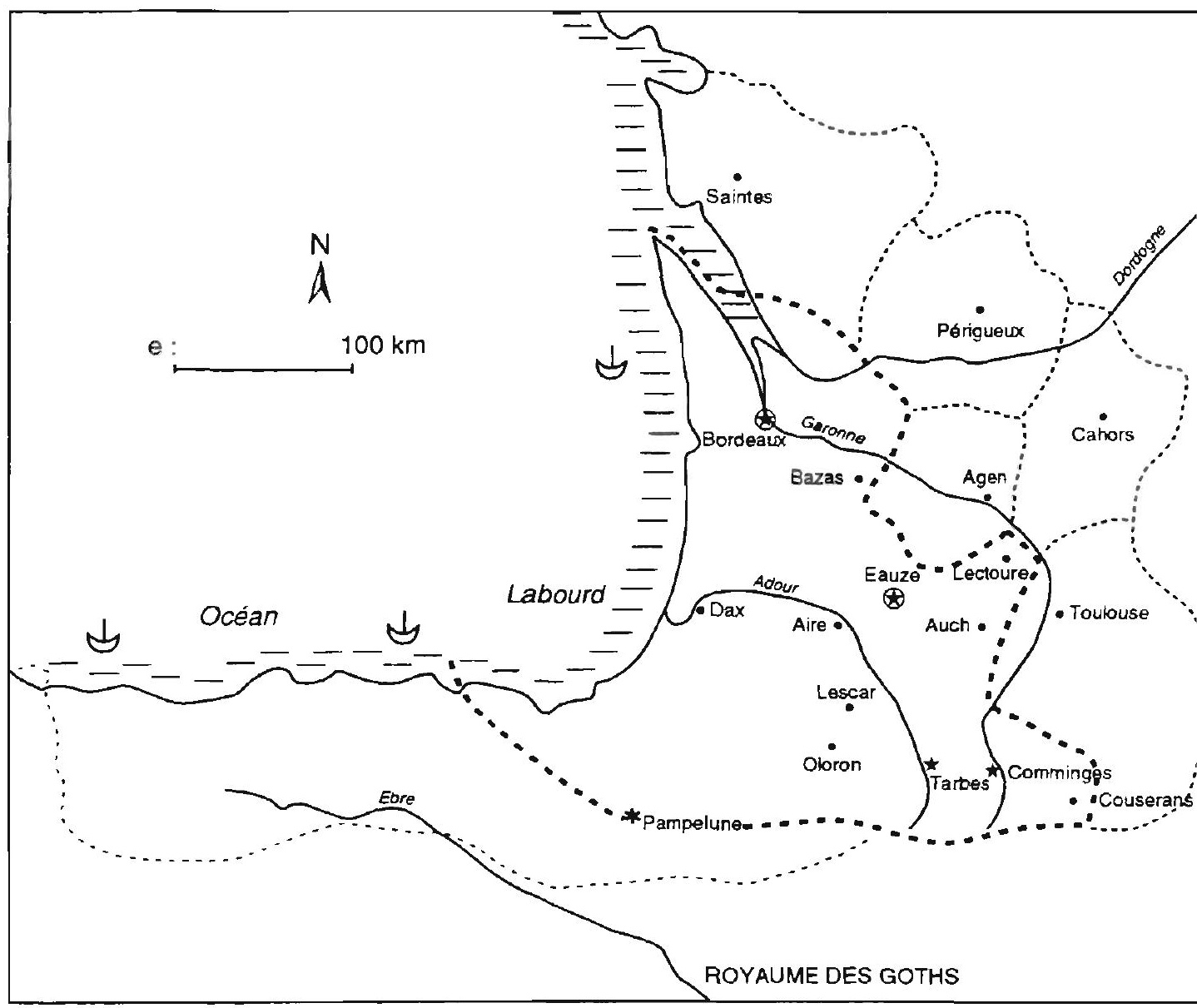

Limites du duché de Wasconia au début du VI" siecle:

Limites du duché cantabre franc avant 612 :

Les comtés du royaume de Charibert 630/632 :

Métropole $\bigcirc$ cité • château $\star$

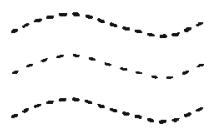

cité de limes *

\section{Les premiers ducs en Wasconia}

Genial 602

Aegyna 626

(Charibert 629/632)

Aegyna 636 
Le terme Vascones existe toujours en Espagne, mais les sources gothiques ellesmêmes, cela a été noté plus haut, font usage du terme Wascones lorsqu'il s'agit des habitants de la Wasconia franque. Les textes francs, notamment Frédégaire très précieux témoin de ce temps, utilisent désormais le terme de Wasconia, Wascones pour désigner les lieux et hommes d'un duché franc. D'autre part, le génitif pluriel Wasconorum fait son apparition, indiquant que Wasco pourrait aussi s'effacer devant Wasconu.S/Wasconi, ce que les textes n'enregistrent pas car il y est toujours, tant au nominatif qu'à l'accusatif, question de Wascones ${ }^{41}$. Ce terme désigne, dès 602 , tous les habitants du duché de Wasconia et l'on ne peut prétendre que tous soient descendus des Pyrénées, éliminant les anciens habitants. Ce qui est évident c'est que ces montagnards servent de référence à tous, que leur nom est devenu symbole d'unité, ce qui se vérifie aisément.

En 626, on apprend que l'évêque métropolitain d'Eauze, Sidoc, ainsi que son vieux père l'évêque d'Aire, Palladius, manifestent leur plein accord (conscii) avec ces mêmes Wascones, leurs ouailles, accusés d'insoumission aux nouvelles décisions de Clotaire II ${ }^{4 !}$. Or ces Wascones et le métropolitain d'Eauze sont dénoncés par leur propre duc, Aeghyna, qui réside peut-être à Bordeaux. Le motif de la « rébellion » est bien évident. En vertu des décisions royales prises à Paris le 18 octobre 614 , il a été précisé, au chapitre 12, que les responsables laïcs des cités comtes et ducs, seraient désormais recrutés dans la région qui leur est confiée. Le roi Clotaire II trouvait en cette disposition une assurance de leur pleine soumission et responsabilité. Il avait ajouté au chapitre 24 que quiconque irait à l'encontre des décisions prises subirait la peine capitale $^{43}$. Or ce même Aeghyna, qui dénonce l'accord des pieux évêques avec les fidèles dont ils ont la charge, n'appartient pas, il s'en faut de beaucoup, au peuple des Wascones puisqu'il est saxon ${ }^{4}$. Les demandes de la région ne font que souligner la contradiction entre l'édit royal et la pratique. Les évêques régionaux ne pouvaient que soutenir cette action, puisqu'ils appartenaient au groupe épiscopal qui fit les frais de la montée de la puissance comtale souhaitée par le roi Clotaire II. L'évêque d'Aire, Palladius, avait lui-même souscrit à Paris, le 10 octobre 614, des canons conciliaires qui préservaient un peu de cette ancienne puissance épiscopale reconnue depuis le temps de Constantin. Il n’avait sans doute pas encore regagné Aire, accompagné de son métropolitain, de celui de Bordeaux et de quatre autres évêques de Wasconia, lorsque le roi, modifiant sensiblement les canons conciliaires, avait introduit ce nouvel article dans son édit.

Les Wascones qui auraient dû recevoir un duc issu de leur région demandent la pleine application de l'édit. Sidoc et son père, jugés indésirables par le roi qui écouta Aeghyna, furent astreints à vivre ailleurs qu'en Wasconia, mais on ne put leur retirer leur titre. Sidoc assista au concile de Clichy tenu presque au même moment, accompagné d'un seul évêque, celui d'Auch, le 27 septembre 626 ou 627 . Le canon 4 soutenait l'édit royal de 614 et le canon 27 prévoyait la peine d'excommunication pour les administrateurs royaux, comtes et ducs qui iraient à l'encontre de ce même édit ${ }^{4}$. Quelle avait été I'attitude du métropolitain de Bordeaux, lui aussi concerné par les édits royaux? Arnégisile était présent au concile de Paris en 614, mais fort curieusement aucun métropolitain de Bordeaux n'est mentionné en 626/627 à Clichy où la cité de Bordeaux - l'Eglise ou le duc- a délégué le diacre Samuel, lequel ne souffle mot d'un éventuel évêque qu’il serait censé représenter comme cela est de coutume. Le duché de Wasconia est le premier à demander, en vertu des édits royaux, un duc issu de sa terre, c'est l'enseignemęnt essentiel des événements de 626 en Wasconia. 
Une identité régionale est née, appuyée comme toute son histoire sur la montagne, et sans doute fortifiée par un afflux de montagnards pendant le VI' siècle. C'est qu'il existait dans la province des Neuf Peuples des terres disponibles, celles que les Goths abandonnaient peu à peu. Certes tous les Goths ne sont pas partis et la toponymie les repère encore pendant la période franque. Mais ceux qui sont partis ont laissé derrière eux de vastes terres souvent négligées et qui avaient besoin d'une remise en état. La compétition a été ouverte entre les Francs qui ne s'installèrent qu'en petit nombre au $\mathrm{VI}^{c}$ siècle et parfois de façon provisoire et les montagnards proches. Achats avantageux peut-être mais plus assurément successions et alliances ont mêlé les derniers Goths eux-mêmes en partie «provincialisés » aux partenaires régionaux. Les montagnards furent le levain de ce nouveau peuple et lui servirent d'éponyme. Ils firent revivre les vieilles traditions, rendirent aux Neuf Peuples une partie de leur mémoire car les temps pré-romains avaient connu ici et là de semblables fondements, c'est ce que montrent traditions et toponymes les plus anciens. Le duché renouait en termes nouveaux avec une histoire antérieure à la romanité. C"est une des particularités de cette époque et cela en bien d'autres régions. Le "duché" est une forme de pouvoir et d'assise territoriale parfaitement bien adaptée à cet exemple régional. Les Wascones constituent un peuple unifié qui manifeste dès le début du VII' siècle, c'est-à-dire dès la mise en place du duché portant leur nom, esprit d'initiative et sens politique. Le royaume franc est pour l'heure unifié lui aussi et il peut encore surveiller ce pouvoir montant. Mais jusqu'à quand ? Jusqu'où ? Lorsque Dagobert succéda à son père, il comprit la situation. Il allait inventer un royaume auquel ses prédécesseurs n'avaient pas songé.

Le règne de Dagobert (629-639) tenta un renversement de la situation. La Wasconia constituée en duché était forte, le pouvoir de Dagobert longuement préparé en Austrasie puis en Bourgogne, plus difficilement établi en Neustrie, n'avait guère eu l'occasion de s'y manifester. Les régions du sud de la Loire, c'est-à-dire l'ancien royaume visigoth, avaient toujours été découpées depuis la succession de Clovis, entre les différents royaumes du Nord, permettant à chaque roi franc de se dire héritier des Goths. Cet héritage gothique fut amplement revendiqué par Dagobert qui profita en 631 de l'avènement de son candidat au trône d'Espagne, Sisenand, pour se faire restituer une part du trésor des Balthes ${ }^{4+1}$. Mais son efficacité politique lui suggère d'utiliser les terres sud-ligériennes au mieux de ses ambitions. Or, il est gêné dans sa succession de Clotaire II par l'existence de son frère germain puîné, Charibert II. Il crée pour lui deux lots dont la dévolution finale s'acheva au tout début de l'année 630 (entre le 9 mars et le 8 avril). ll concéda ainsi à son frère en un premier temps le duché de Wasconia, remis pour sa subsistance, puis cinq comtés dont il fit l'assise d'un royaume ${ }^{43}$. Cela constituait au total un assez beau territoire dont la création mérite quelque explication.

Dagobert désamorce par cette fondation le parti qui derrière Chariber Il et son oncle matemel, Brodulf, s'était élevé, dans des querelles de cour, contre le duc Aeghyna, et jouissait de ce fait d'un certain crédit auprès des Wascones ${ }^{48}$. Pour empêcher tout retour possible d'un danger, Dagober fit assassiner Brodulf au sortir du bain ${ }^{49}$. Mais ce n'est pas le plus important. Pour lui, le duché de Wasconia est mort, et il confie son territoire à Charibert, à titre privé, pour sa subsistance, en une première concession territoriale bien distincte du reste, relevant d'un droit différent du reste de la dotation, et n'ayant pas le même statut. La Wasconia n'est pas constituée en royaume mais en apanage, terre dans laquelle le roi des Francs est toujours susceptible d'intervenir, qu'il peut reprendre selon l'occasion. La concession est faite à titre privé et il n'y a pas dévolution des droits politiques. Dagobert inaugure semble-t-il, une défini- 
tion allodiale de la Wasconia, partie intégrante du royaume franc, où le roi franc détient la puissance publique, mais qui est le bien propre des Wascones ou de leur chef. En dehors de la Wasconia, le roi accorde à Charibert un petit royaume formé de cinq comtés, non plus pour sa seule subsistance mais pour exercer un gouvernement royal (hoc tantum regendo concessit : c'est cela seulement qui lui fut donné pour qu'il le gouvernât). Dagobert vient de créer un royaume qui isole son propre territoire de celui de la Wasconia, mais surtout il tente de noyer le duché en le plongeant dans une plus vaste étendue de terres, reprenant la vieille arme utilisée jadis par Auguste pour pacifier les Aquitains du sud de la Garonne et cela fut si sensible au chroniqueur Frédégaire qu'il retrouva à cette occasion le terme cré par Auguste d' " Aquitanique ».

Le temps du court règne de Chariber qui mourut le 8 avril 832 et fut rapidement suivi dans la tombe par son jeune fils, le tout ayant été organisé par Dagobert, est d'un très grand intérêt. Le chroniqueur rapporte la soumission complète des Wascones à la puissance de Charibert, et l'interprétation de ce passage mérite lui aussi un temps d'arrêt, tant le message transmis par Frédégaire est riche ${ }^{\text {so }}$. Les historiens y ont dans l'ensemble vu la preuve d'une insoumission permanente des Wascones, vantant l'astuce de Dagogert qui aurait concédé ce qu'il ne détenait pas. Or Frédégaire ne parle pas de rébellion. Il parle d'une prise de pouvoir (redegit) ce qui ne peut être fait qu'aux dépens de celui qui le détenait. Cette terre remise selon le droit privé (ad instar privato habiiu), était restée dans la puissance politique de Dagobert. On voit en effet ce roi user de ses droits publics en Wasconia, surveiller les activités du missionnaire Amand dans les confins des Pyrénées (non point pour apporter l'Evangile mais pour combattre les effets des diverses hérésies développées depuis longtemps au contact d'une région d'Espagne déchirée par les nombreux compétiteurs au trône) ${ }^{\text {s. }}$. Puis, rappelant Amand, il convoquait Charibert à Orléans pour les fêtes baptismales de son fils Sigebert ${ }^{\text {s2 }}$. Cette situation de dépendance ne devait satisfaire ni Charibert II roi d'un dérisoire royaume de cinq comtés, ni les Wascones. Charibert, avec son armée convoquée sur place, installa donc ses propres droits contre ceux de Dagobert au printemps de l'année 632, sur la Wasconia. Il mourut peut-être au combat ou fut, comme son jeune fils Childéric, victime de la "faction de Dagober" \$? La Wasconia demeurerait alleu dans le territoire et dans la puissance publique du roi des Francs. La guerre déployée sur son sol était une fois de plus une guerre politique.

Le succès du parti de Charibert en Wasconia trouverait une explication selon une tradition rapportée par la charte trop discutée d'Alaon. Cette charte fait en effet état du mariage régional de Charibert, union dans laquelle prendrait racine la suite de l'histoire des pouvoirs en cette région. Par son mariage avec Gisèle, fille d'un duc Amand, Charibert et plus encore son lignage se seraient acquis des droits héréditaires en Wasconia $^{4}$. Si l' on en croyait une partie des enseignements de la charte d'Alaon, il serait intéressant de noter que, comme dans le texte de Frédégaire, la Wasconia est traitée à part des autres terres de Charibert qui y aurait recueilli l'héritage d'un duc particulier. Après son décès, Dagobert héritait du royaume de son frère et aussi de la Wasconia, indiquée à part. Il évinçait son neveu Childéric de la succession tant royale que privée. Il se faisait remettre le trésor ${ }^{s}$.

\section{7-637 : Cinquante années décisives}

Dagobert reprenait donc possession directe de la Wasconia, y remettait en place un duc, mais ce fut, hélas !, le redoutable Aeghyna qui entra de nouveau en fonction. Il arriva ce qui devait arriver : la « rebellion » des Wascones, qui s'opposèrent à la spo- 
liation tout à la fois d'une descendance de Charibert et Gisèle selon la charte d'Alaon, et des Wascones appuyés sur l'ancien édit de Clotaire II que Dagobert n'avait pas abrogé. Le même mot de "rébellion » est utilisé par le chroniqueur Frédégaire pour l'année $633 / 634$ comme pour l'année $626^{6 \%}$. C'est l'avant-dernière mention des événements de Wasconia dans l'œuvre du chroniqueur et elle contient des éléments qui constituent la conclusion de toute l'époque de mise en place de la Wasconia que nous venons de vivie.

Après le décès de Charibert, la révolte a surgi contre Dagobert et ses ducs, des pillages ont été commis, non en Wasconia, mais dans les terres du « royaume des Francs » dont Charibert II fut roi, ce qui souligne encore la différence essentielle entre Wasconia et royaume « aquitanique " s'il en était besoin. Dagobert ne voulut pas risquer une intervention de l'Eglise dans cette affaire. On ne connaît d'ailleurs pas de nom d'évêque en Wasconia pour cette période. Il prit les devants et envoya sur place la plus forte des armées jamais levées dans son royaume, qu'il confia au référendaire burgonde Chadoin. Bien évidemment Aeghyna le Saxon était parmi les généraux mais aussi ceux qui quelques années plus tôt avaient assassiné Brodulf, les ducs Amalgaire et Arimbert et le patrice burgonde Willibald, dix corps d'armée au total et des comtes munis de commandements, armée si importante qu'à son retour de Wasconia il suffit d'en menacer les Bretons pour obtenir leur reddition sans combat ! ${ }^{57}$.

L'armée entre donc en 635 en Wasconia dont les habitants, quelque peu obstinés, veulent un duc choisi parmi eux, comme neuf ans plus tôt. Ils auraient, selon la charte d'Alaon déjà évoquée, un possible candidat dans la succession de Charibert et de son épouse, elle-même issue d'un lignage détenteur de puissance régionale, ce qui rendrait leur combat plus vigoureux, plus appuyé. Et il le fut. La défaite du duc Arimbert en Soule, inimaginable, n'aurait cependant pas brisé les résultats d'une campagne jugée victorieuse par le chroniqueur qui devient à cette occasion presque poète. Une vallée de cette Wasconia souvent vue en bloc et qui de texte en texte laisse apercevoir châteaux et évéchés, Labourd, Dax, Eauze, Aire, Bigorre, est nommée, c'est la Soule, qui est la forteresse naturelle d'une Wasconia elle-même forteresse humaine. Un mot voisin de celui qu'avait utilisé Grégoire de Tours trois quarts de siècle plus tôt est choisi par Frédégaire (prorumpentes, properant) pour montrer les montagnards qui jaillissent de la montagne et savent y attirer l'ennemi, tandis que, quelques lignes plus loin naît de la plume du chroniqueur le spectacle des vallées ténébreuses, des rochers suspendus, pays jadis appelé saltus, mais le mot n'est pas repris tant il y a désonnais de respect pour ses hôtes. L'armée serait rentrée sans dommage dans ses foyers si Arimbert n'avait pas commis l'erreur de poursuivre l'assaillant en Soule, gémit Frédégaire qui pleure alors tous ces hommes nobles et expérimentés qui avaient eu le même sor que le duc. Pourtant les Wascones sont soumis, doivent accepter le retour d'Aeghyna comme duc, et Dagobert fête à Clichy la victoire de son armée. Frédégaire n'en reconnaît pas moins que cette armée a dû combattre un ennemi d'une cohésion telle qu'il décerne spontanément le titre de "patria " à la Wasconia. ${ }^{58}$

Les Wascones étaient présentés comme des groupes incontrôlables dans l'œuvre de Grégoire de Tours et de ce fait mal définis. Cinquante ans plus tard ils ont donné naissance à une « patrie ». Ce terme demande à être précisé et il ne faudrait pas le comprendre comme seulement la terre occupée par les aïeux, ce qui ne correspondrait pas à l'usage qu'en firent les hommes de ce temps. Les auteurs du début du VII' siècle utilisent souvent ce terme associé à celui de gens. Parfois, le couple de mots patria/gens a comme équivalent populus/terra ce qui, dans l'un et l'autre cas associe un peuple et un territoire. Frédégaire fait de même et c'est le dernier mot de sa chronique qui soit 
relatif à la Wasconia : "Wascones regressi sunt in terram Wasconiae "*. Cela nous invite à comprendre le mot " patrie » comme représentant le territoire choisi et tenu par un peuple pour en faire sa résidence. La patrie d'un peuple fait son apparition lorsque ce peuple est installé. Elle n'est pas nécessairement immuable, ancienne, mais elle peut être le résultat d'une action. On avait ainsi vu par le passé le peuple des Goths en quête d'une patrie qu'ils ont un certain temps trouvée dans les Gaules et qu'il sont en train d'achever dans les Espagnes au début du VII' siècle. La patrie des Wascones est le territoire du « duché » dont ils sont éponymes et qui correspond à leur résidence. Mais il faut corriger cette définition trop administrative en soulignant que cette patrie est ressentie comme le bien commun d'un peuple qui y a établi ses traditions autant que ses hommes, qu'elle est refuge, centre de vie, et désormais patrimoine.

Le peuple appelé peuple des Wascones s'est constitue, comme tous les peuples du monde, au cours d'une histoire qui est aussi une ethnogenèse. $\Pi$ ne correspond pas aux Vascones du temps de Strabon. Il mêle au début du VII' siècle les anciens « provinciaux " du royaume gaulois gothique, qui sont les novempopulaniens eux-mêmes constitués de Celtes, Celtibères, Romains (mais qu'est-ce qu'un Romain ?), aux Goths, eux-même fort mêlés ${ }^{6)}$. A eux se sont joints différents peuples réputés barbares parmi lesquels les Suèves, quelques Hastingues. Des Cantabres ont rejoint leurs rangs à divers temps de l'histoire, et notamment au temps du duché franc. On y trouve des Saxons dont l'intégration est parfois difficile, mais aussi parfois réussie. Les Francs, au VII" siècle constituent le dernier appont, mais cette « ligue franque » est elle-même des plus hétérogènes. Les montagnards enfin ont servi de fil rassembleur pour nouer toute cette moisson humaine. Leur nom s'attache désormais à une terre. La patrie de Wasconia est née.

Sa formation explique l'originalité de ce peuple, mélange solide, conscience soudée. Les Wascones ont une telle personnalité de groupe qu'ils sont susceptibles de prêter un serment collectif après la campagne de 635. Frédégaire, dans son demier chapitre consacré à la guerre de Wasconia, éclaire leur portrait. Dans l'attitude peu exaltante de la soumission que décrit le chroniqueur, quelques traits de plume retiennent l'attention ${ }^{61}$.

Il apparaît alors nettement que les Wascones se sont présentés au printemps de l'année 637 au plaid de Clichy pour vider la question qui les inquiète depuis 626, à savoir celle de leur duc. Le duc Aeghyna, qui aurait dû les représenter et leur éviter le voyage, se tient à côté d'eux mais non comme leur chef. Les Wascones, eux, ont délégué leurs propres ambassadeurs et ceux-ci ne laissent pas d'étonner. Il s'agit de tous ceux qui appartiennent à un groupe qualifié de "seniores ». C'est un Sénat. Si ]'on compare les termes employés par Frédégaire et ceux que Sidoine Apollinaire avait employés pour le Sénat des Goths qu'il vit réuni à Toulouse, on a l'assurance qu'il s'agit bien de la même institution. Le Sénat gothique était une assemblée représentant le peuple des Goths, il siégeait debout, en vêtement guerrier. Dans le récit de Frédégaire, aucun mot ne signale une prosternation, une position de soumission de ces hommes devant le roi. Ce Sénat est venu au complet (omnes) et son objectif demeure le renvoi du duc Aeghyna, présent lui aussi devant Dagobert mais distinct de leur groupe. Les Wascones se placent sous la protection de saint Denis, puis se présentent au roi. Le chroniqueur invoque alors l'indulgence, la clémence royale et les serments prêtés par les Wascones dont il dit immédiatement qu'ils n'ont leurré personne. L'attitude des Wascones a engendré un plein succès de ce qui fut finalement une ambassade : ils retoumèrent dans leur terre. mais délivrés d'Aeghyna qui ne les suivit pas et que l'on retrouve peu après dans le conseil du roi, mais non en Wasconia. 
Les Wascones se sont conduits à Clichy comme les successeurs de ces Vesi (aristocratie guemière) goths qui avaient constitué le Sénat gothique et gouvemé avec les rois Balthes. Comme les Goths des temps les plus anciens ils considèrent la demande de serment comme irrecevable dans le domaine politique et agissent en conséquence, les Francs l'ont remarqué suggère Frédégaire. L'existence du Sénat de Wasconia est dans la même lignée. Cette institution explique le poids des décisions prises par les Wascones, leur stratégie múrie, leurs prises d'armes calculées, leurs objectifs politiques diffusés d'un bout à l'autre de la Wasconia. Il faudra désormais compter avec lui, puisqu'il est un organe de gouvernement. Il siège peut-être plus facilement à Eauze qu'à Bordeaux, ce que laisse entendre l'attitude de Sidoc, à moins que cela ne soit dans l'ancien palais des Goths à Aire ou dans une forteresse, Labourd, Tarbes, Palestrion, ou toute cité forte, selon les nécessités du moment, et comme le firent les Goths qui entretinrent et construisirent forteresses, villa et palais.

La Wasconia est née, définie par un peuple, une terre, une assemblée. Il ne lui manque plus qu'un chef régional accepté par les rois Francs et qui ait leur confiance. Restera-t-elle duché, deviendra-t-elle principauté, ou son destin sera-t-il uni à celui de l'Aquitaine nord-Garonnaise ? Elle a, dès le premier tiers du VIl' siècle, toutes les structures nécessaires pour contribuer à sa propre histoire. Bien que ne représentant pas un cas unique, elle est l'une des premières régions du territoire des Francs à révéler son organisation, ses traditions. 


\section{Les rois francs}

\section{Clovis}

$\div 511$

Clotaire $\mathrm{I}^{\sigma}$

$\div 561$

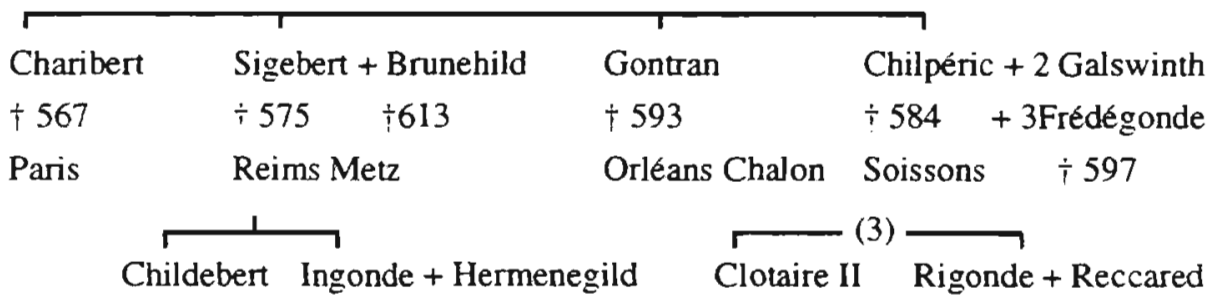

Austrasie + Bourgogne 593

Neustrie puis le reste 613
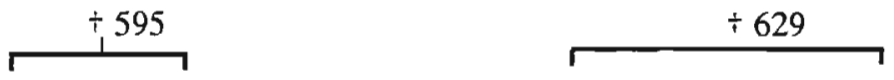

Thibert II

Thierry II

Dagobert

Charibert II

Austrasie Bourgogne Austrasie 612 les 3 royaumes «Aquitaine»

Wasconia

$\div 612$

$\div 613$

$+639$

$\uparrow 632$

succession évincée 


\section{Les rois goths}

Royauté héréditaire des Balthes dans les Gaules

$\triangle$ Théodoric $I^{\circ}$

$\div 451$

\begin{tabular}{|c|c|c|c|}
\hline $\begin{array}{l}\Delta \text { Thorismond } \\
\uparrow 454\end{array}$ & $\begin{aligned} \Delta & \text { Theodoric II } \\
& \div 466\end{aligned}$ & $\begin{array}{l}{ }^{\Delta} \text { Frédéric } \\
+460\end{array}$ & $\begin{array}{l}{ }^{\Delta} \text { Euric }+ \text { Ragnahild } \\
+484\end{array}$ \\
\hline & & & $\begin{array}{l}{ }^{\Delta} \text { Alaric (2) +ैAriane } \\
+507\end{array}$ \\
\hline
\end{tabular}

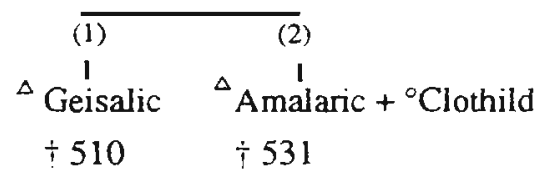

Royauté semi- héréditaire en Espagne

Athanagild + (1) $\ldots . .-$ Goswinth $\cdots+. .-(2)$ Leovigild $+(1)^{\circ}$ Théodosia $\div 566+5889$

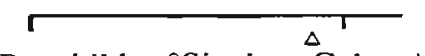

${ }^{\circ}$ Brunhild $+{ }^{\circ}$ Sigebert Galeswinth $+{ }^{\circ}$ Chilpéric (2)

${ }^{\circ} \mathrm{Childebert \quad} \mathrm{Ingonde}$ ${ }^{\circ}$ Hermenegild $\quad{ }^{\circ}$ Reccared $+{ }^{\circ}$ Rigonde

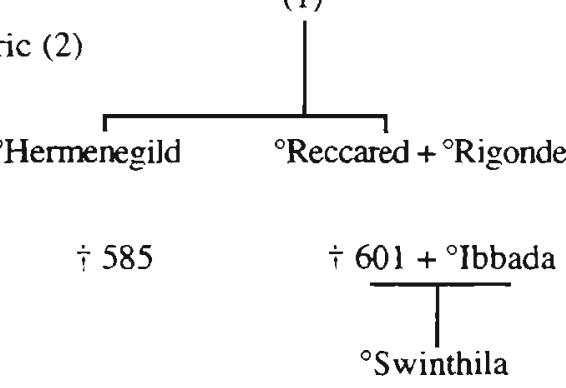

Royauté élective en Espagne

$$
\begin{gathered}
{ }^{\Delta} \text { Witteric } \\
\div 612 \\
\hline{ }^{\text {oSisebut }}
\end{gathered}
$$

Religion : arienne gothe : $\Delta$ catholique : ${ }^{\circ}$ 


\section{N OTES}

1. Grégoire de Tours, «Historianum Decem Libri», L. LX ch. 7 et 20, ed. B. Krusch, Monumenla ívermaniae Historica, (ensuite dits M.G.H.) Scriptores Rerum Merowingicarum, 1. 1, 1885, pp. 283 et 448. *Wa.5. cones vero de montibus prorumpentes in plana descendunt. vineas agrosque depopulantes, domos tradentes incendio. nonnullos abducenses captivos cum pecoribusw, et «Pari condicione. civitates Meldus et duas porciones de Silvanectis. Thoronus. Pectavis, Abrincatis. Vico Julii. Consorannis, Laburdo et Albige domnus Childebernus rex cum terminibus a praesenti die suae vindicit potestate. $\mathrm{La}$ traduction se trouve plus loin, dans le texte.

2. M. Rouche, L'Aquitaine des Wisigoths aux Arabes, Paris 1979, à la suite de beaucoup d'autres.

3. R. Mussol-Goulard, Les Princes de Gascogne, Marsolan, 1982.

4. R. Mussot-Goulard, Histoire de la Gascogne, P.U.F., 1996.

5. Par exemple le long sejour dans le sud des Gaules, après Vouillé, de Geisalic, frls aîné d'Alaric II suivi de sa mort dans les régions rhodaniennes.

6. *Concilia Galliae», ed. Ch. De Clercq. Corpus Christianorum, series lanina, 148, Tumhout, 1963, pp.4-19

7. "Vita Parum" (vie de saint Quintien), IV, 2, ed.B. Krusch, M.G.H. Scriptores Rerum Merowingicarum, 1, 2. Bcrlin 1885. IV, 2, p.675.

8. Grégoirc de Tours op. el ed. cit. livre V chapitres 33 et 34 . Année 580 : «La ville de Bordeaux fut secouéc d'un tremblement de terre qui ébranla les remparts de la cite... Ce uremblement se repandit jusqu en Espagne... des sommets des Pyrénées roulerent d'immenses blocs de picrres qui renversèrent les troupcaux el les hommes... Ces prodiges furent suivis de près par une épouvantable épidémie..* . Peste que souligne cgalcment, en 583, en Espagne, Maxime de Saragosse, "Chronicon * ed. J.P. Migne, Patrologie latine, t. 80 cc.625-630. Sur * l'imposteur * que Grégoire dépeint comme un ivrogne nauséabond, de langage grnssier. de costume extravagant, Grégoire de Tours, op. et ed. cit., L. IX, chap. VI. Sur le rôle d'Amélius et l'affaire Gondovald, Jiden. L. VIII, chap. 28, et L. VII chap. 35.

9. Grégoirc de Tours. Livre IX chap.7. voir première partic de la note 1. La première mention de la Wasconia se situe en 581 , voir note 11 .

10. Maxime de Saragosse op. et ed. cil. Anno 579 * Ingundis. Sigeberi et Brunehildis Franciae regum filia. virgo pulcherrima, sexdecim annos nata, ex Francia in Hispaniam deducitur, eam comilantibus Euphemio metropolitano cpiscopo mulisque viris palatinis Hispaniae et Franciae et episcopis, videlicet ForIunato Pictaviensi. Salvino Albigensi. Faustiano Aquensi, Beltrano Burdegalensi et Gregorio Turonensi qui in presentia istorum. Toleti aede sanctae Mariae, nubil Hermenegilde in ipso anni principio *. "Ingonde, fille de Sigebert et Brunchild rois des Francs, vierge très belle agé de scize ans fut conduite de France en Espagne. L'accompagnaient l'évêque métropolitain Euphémius ct de nombreux personnages du palais tant d'Espaguc que de France ainsi que les évêques Fortunal de Poitiers, Salvien d'Albi, Faustien de Dax, Bcrtrand de Bordcaux cı Grégoire de Tours qui en présence des mêmes la maria à Herménégild au début de la même année en l"Église Saintc-Maric de Tolede $\%$.

11. Gregoirc de Tours. op. et ed. cit. Livre VI, chap. 12 : "Quant au duc Bladaste, il partit en Wasconict ct perdit la plus grande partic de son armee * en 581. Rien ne dit contre qui Bladaste guerroyait au nom de Chilpéric. En 587, Livre DX chap. 7,8 pour Ennodius ct Austrovald.

12. Rence Mussot-Goulard, "Marginalite et integration des Gascons dans le monde franc " in Minorites el marginaux en Espagne et dans le midi de la France. C.N.R.S., 1986, pp. 15-32.

13. Les differcnts passages relatifs a la vie de Sertorius foumissent quelques indications sur la sociétc ct la culture desVascones. Les enquêtes archcologiques seraient les bien venues pour connaître l'habitat, la vic quotidienne, et peut-être expliquer lc qualificatif * fibularenses » des habitants de Calagurris. On n'a pas retenu ici le subicriuge d'Isidore de Séville. Enmologiarum Libri XIV, (LX 107) qui, pour des raisons bien compréhensibles en son temps veut confondre les Vascones et les Vaccei. Une lecture attentive des auteurs anciens nous a pcrmis de conclure a l'cxistence de deux peuples distincts. Nous ne reviendrons plus sur cette question (voir note 12).

14. Strabon. Géographie, ed. F. Lasscrrc, 1966. livre IIl, 4, 9. * Ilerda et Osca dépendent des Ilergètes. C'cst dans ces deux villes que Sertorius livra ses dernicrs combats ainsi que dans celle de Calagurris. chez les Ouaskoonool' et sur la côte à Tarragone... Par ces villes (Osca et Ilerda) passe la route qui de Tarragonc conduit aux derniers pcuples Oulaskoonooï riverains de l'Océan, par Pompelona/Pampelune ct jusqu'à Oyarzun. Celle routc s'arĉte à la frontic̀re entre l'Aquilaine ct l'Ibérie... Le peuple des Ouaskoonooi avec la ville de Pompelona. c'est-à-dirc la ville de Pompee * Pour le genre de vie montagnard, $I b i d e m$ Livre III. 3. 7 
15. Tite-Live, Histoire Romainc, ed. P. Jal, pp. 214/218. Lucius Annaeus Florus, Tableau de l'histoirc du peuple romain de Romulus ¿ Auguste, ed. P. Jalabert, 1967. Livre II, 10, reprend le récit de la gucre de Sernonius et précise que depuis 27 av. J.C. Ics peuples des montagnes se rendent aux assemblées dans les villes de plaine. Valère-Maximc, Neuf livres des faits et paroles mémorables, Livre VII, 6, 3, ed. et trad. M. Nisard, 1864,p. 747, fait lc portrait des Calgurrtains : « Il n'est pas de serpents ni de bêtes féroces que l'on puissc lcur comparer ". Juvénal, Satires, ed. P. de Labriolle, F. Villencuve, 1971 puis J. Gérard, 1983, accordc un rcgard different aux Calagurritains qu' il nomme Vascones, Satura XV, pp.192/193 : “... Quisnam hominum venian dare quisve deorum urbibus abnueret dira atque inmania passis..." ?

(Qucl homme nu quel dicu refuserait le pardon à des villes qui ont souffert de tels maux ?). Puis il ajoutc au vers $113: \rightarrow$ Nobilis ille tanien populus.... (Ce noble peuple..)

16. César, Commentaires sur la guerre des Gaules, Livre III chapitres 20 à 22 pour les combats de Sos, puis chap. 23 : * Les Barbares.. envoient des députés aux pays d'Espagne Citérieure voisine de l' Aquitainc..... Ils choisissent des chefs parmi les guerricrs qui avaient longtemps combattu avec Quintus Senorius et qui passaient pour très habiles dans la tactique militaire. Ils avaient l'art de prendre position, de se fortifier. de couper les vivres aux ennemis, de tenir les routes... *

17. Paul Orose ignore le nom des Vascones. Sa gégraphie suit de près Polybe, et sa guerre de Sentorius doil tout a Plinc et a Valère-Maxime. Historia adversum paganos, Libri I, V, VI et pour Calagurnis Liber V chap. 24. ed. J.P. Migne, Patrologic Latine, t. 31, C. 35.Il est en revanche précieux pour l'histoire evénementiclle de son temps.

18. Tacite, Hisioriarum Libri V, Liber IV. c h. 33 ed. H. Goclzer, 1939, p. 243 : * Vasconum lectae a: Galba cohortes ac tum accitae. dum castris propinquant, audito proeliantitum clamore intentos hostis a tergo invadunt latioremque quam pro numero terrorem faciunt, aliis a Novaesio, aliis a Mogontiaco universas copias advenisse credentibus $»$.

19. Caius Plinius Secundus. Historiae Nauralis Libri XXXVII, L. IV, 34, : * A Pyrenae per Oceanum. Vasconum saltus. Olarso... * et L. III, 22, «... recedentes radice Pyrenaei, Ausetani, Iacetani perque P.renaeum Cerretani, dein Vascones... " et L. III, 24, la liste des représentants des villes au Conventus de Saragosse. ed. Locbb. 1957, p. 20.

20. Ptolemée, Géographie. L II. 6,10, et 6,66. ed. Firmin Didot, 1883 pp. 148 et 189/191.

21. Ausone, leture XXIX à Paulin, vers 51/52, «Vascones hoc saltus et ninguida Pyrenaei Hospitia et nostri facit hoc oblivio caeli? "

Paulin, lettre X a Ausone. vers 205/231 plus particulièrement. Episiulae, ed. W. Hartel. Corpus Scrip. vurum Eccicsiasticorum Latinorum, $\mathrm{n}^{\circ} 29.1894$. L auteur tente d'apaiser la vision cffrayante du sattu, : : St vascone saltu quisquis agit puru.s... » et remarque quc ce saltus de Vasconia (une des premières mentions de la Vasconia aux années 390) est la premuère région d'Espagne rencontrée en venant des Gaules * VaLconiae saltus el ninguida Pyrenaei obicis hospitia in primo quasi linute fixus Hispaniae regionis..."

22. La sculc definition acceptable des Germains est celle qui a éte donné par un de leurs contemporains. Paul Diacre, témoin de l'arrivée du peuple " germanique " des Lombards, "Historia Langobardorum " cd. G. Barni. 1975. Nom (forme sur Gê, la terre,) désignant des hommes vivant à l'état de naturc. proches de la tcric. des arbres, des eaux.

23. E.A. Thompson, "Peasant revolts in late roman Gaul and Spain ", Past and Present, 2, 1952.

24. Les événements de 443.449 et 454 sont rapportés par Hydace, Chronique, ed. A. Tranoy. 1974. aux paragraphes 128, p.139: 140. p. $143 ; 158$, p.149. Lc pillagc suèvc est indiqué en ces termes : « $R c$ chiarius. accepta in conjugium Theodorici regis filia. auspicaus initium regni Vasconias depracdarur mense februario " (Rechiarius, ayant accepté la fillc du roi Théodoric comme épnuse, inaugura son règne en ravagcant Ies Vasconias). Pour les campagnes ordonnées par Euric, "Chronica Gallica *. paragraphe 65I. ed. Th. Mommsen. M.G.H. Auctores Antiquissimi, IX Berlin, 1892 p. 664.

25. Taïon, ćvēque de Saragosse. « Sententiarum Libri Quinque «, Praefatio, ed. J. P. Mignc. Putrologie latine, t. 80 c. 727 : En 649. lcs Vascones et le goth Froia contre le roi Receswinth.

26. Description de l'" honor " du diocese de Labourd a l'orce du XI" siccle (charte d'Arsieu) A.D. Pyrénécs Allaniques G.1.

27. Frédégairc. "Chronique » ed. J. P. Migne. Palrologie Latine, 1.71 c.622 et 623 . Un condensé de renscignements : Eo anno (612), mortuo Betterico. Sisebodus successit in Spaniae regnum, vir sapiens at per totan Spaniam laudabilis valde, pietate plenissimus. Nam et adversus manum publican fortiter dinicavil. Provincian Cantabriam Gothorum regno subegit. quam aliquanto/aliquando Franci possideramt. Dux. Francio nomine, qui Cansabriam tempore Franconum subexerat, tributa francorum regibus multo tempore impleverat. Sed cum a parte imperii fuerat Cantabria revocasa a Gothis, ut supra legitur, pracoccu. patur. el plures civiates ab imperio romano Sisebodus in littore maris abstulit el usque fondamentum des. 
truxil.... Confirmatum est regnum Golhorum in Spania per maris littora usque montes Pyrenaeos. C'est-àdire : Cette année-la, Witteric étant décéde, Sisebut lui succéda sur le trône d'Espagne, homme sage et loué par tous en Espagne. Il sc battit contre la puissance publique établie et soumit au royaume des Goths la Cantabric que, à plusicurs reprises/depuis longtemps, les Francs avaient possédée. Le duc appelé Francio qui gouvernait la Cantabric au temps des Francs avait envoye pendant lontemps des tributs aux rois francs. Mais la Cantabric fut reprise par les Goths comme nous l'avons dit et Sisebut arracha plusieurs forteresses au pouvoir imperial sur le littoral maritime et les détruisit jusqu'aux fondations.....Le royaume des Goths fut ainsi affermi en Espagne, le long de l'Ocćan jusqu'aux monts Pyrénées. "Le duché cantabrique franc du $V^{*}$ siècle est cartographié a la demière page du livre de S. Teillet. Des Goths a la nation gothique. Paris 1984. Il s'čcınd vers l'Ouest jusqu 'à Ovicdo, Leon puis gagne l'Est vers Logroño et Jaca. On signalera aussi la correspondance du pape Grégoire le Grand avec les rois francs dans une renaissance de I'idee impérialc chrétienne à leur profit : Epistula VI, 4, ed.P. Ewald et L.M. Hartmann, Monumenta Germaniae HisIorica. Epistulae, 1. 1, Berlin, 1887.

28. Juan de Biclar, « Chronica ». ed. Th. Mommsen, M.G.H., Auctores Antiquissimi, t. XI, 2, Berlin, 1894. p. 213: (anné 574) "His diebus. Leovigildus rex Cantabriam ingressus provinciae per'asores interfecil. Amaiam occupat, opes eorum pervadit et provinciam in suam revocal dicionem" Juan de Biclar. goth conver au catholicisme et bientôt évêque, est un admirateur de Lcovigild dont il suit les actions, dans sa chronique; d'un tout du règne à l'autre. Pour le titre de duc de Cantabrie et Vasconie chez les Goths, A. Barbero et I. Loring, Historia de España t. 2, 1989 et J. Orlandis, Historia del reino visigodo español, 1988 carte p.86.

29. Grégoire de Tours, Decem libri historiarum, ed. cit. L. VIIl ch. 35.

30. Franci Burdigalam obtinuerunt... caploque Suarrio Gothorum duce » ed. Th. Mommsen, M.G.H Auclores Antiquissimi, t. DX, Berlin, 1891. p. 333

31. Cctte succession des possesseurs du Bordelais et de Dax est ćtablie à partir des présences épiscopalcs auc conciles et selon l' « Histoire des Francs $»$ dc Grégoire de Tours (ed. cil). qui suit avec bcaucoup de précisions les événements dont il fut contemporain. Plusieurs titulaires sont connus pour ce comté, sans oublier la célebbre référence : Venance Fortunat, Camina, ed. F Levison, M.G.H. Auctores Antiquissimi, $t$. IV. Opera Poetica. Hanovre 1881, carmen X, à Galactoire:

burdegalenisis eras el cum defensor, amator....

judicio regis valuisti crescere judex...

debet et ipse potens ut adhuc bene crescere possis

pracstet ut arma ducis qui tibi restal apex

ut patriae fines sapiens thearis et urbes

adquiras ut ei qui dal opina tibi

Cantaber ut timeat. Vasco vagus ama pavescat

atque Pyrenaeac deserat Alpir opem. .

C'cst-à-dirc : « Tu étais le défenseur (litre) el l'ami (titre) de Bordeaux, et tu avais géré dignement ces deux dignites Iorsque le jugement du roi te fit comte. Ce que la renommée avait reconnu à tes mérites, la parnlc royalc te l'a donne. Il doit encore, ce roi puissant, te permettre de continucr. Qu'il tc confie les armes de duc pour que tu défendes les frontières de la patric, que tu gagnes des villes et que le Cantabre craigne. que lc Vasco insaisissable rende les armes et livre la richesse de sa montagne pyrénéenne a celui qui tc comble de biens. « Mais l'on peut préferer la traduction de M. Rouche, op. cit. p. 505, ou celle de M. Fauriel "La Gaule méridionale * 1836, t.2, p.365. ce qui nc change ricn au sens général du texte.

32. Juan dc Biclar, op. cit. cd. cit. p.216, : annce 581 : Leovigildus rexpantem Vasconiae occupat el civilatem quce Victoriacum nuncuparur condidit. "Le roi Léovigild occupe une partie de la Vasconia cl fonde la cilć aujourd' hui appclé cilé de la victoire". Iđcntification de la civitas victoriaca avec Iruña par A. Barbero et A Vigil, Sobre los origenes sociales de la Reconquista, Madrid, 1975.

33. Reprisc de la loi d'Euric (dans les Gaules de 466 a 476) par Leovigild (dans les Espagnes de 568 a 587). On ne prendra qu'un excmple parmi le nombreuscs mentions. » Libcr Judiciorum « ed. K. Zcumer M.G.H., Leger Visigothorum, Berlin 1902, p.369 « Antiqua: Hoc justum eligimus ut. per singulas civitates vel castella quicumque erogator fuerit constitutus, conter civitatis vel annone dispensator (in castellis) an. nonam quam ci dalurus ex inlegro in civilate vel castello jubeat cxiberi et ad integrum eis restituere non morctur... " C'cst-à-dirc : "Loi anciennc : Nous tenons pour justc. dans chaque cité ou château où un responsable de l'annone est ćtabli. que le comte de la cité ou le dispensateur de l'annone distribue sans retar' ct cn totalité dans les citcs ou les châteaux, l'annone qui lui csi confice ».

34. Venance Fortunat. op. ct ed. cit. Carmen IV, 1 à Chilpćric : "Quem Geta. Vasco tremunt. Danus. Enlhio, Saro. Britannus... * et à Justin II. « Germanus, Batavis... *.

35. Vuir la note 31 pour le duché de Bordcaux. 
36. Par cxemple au temps de Recared, cn 621 avec Swinthila ctc.., selon Isidore de Seville, » Historia Gothorum ", paragraphes 54, 59, 63 ed. Th. Mommsen, M.G.H., Auctores Antiquissimi, L XI, Berlin, 1894, pp. 289, 292. Pour Ics Evénements de 649, voir le texte de Taion déjà cite, note 25

37. Isidorc de Séville, op. et ed. cit. paragraphe 59, p. 291. Isidore Écrit régulièrement Vascones sauf dans la mention du combat de Gundemar. II s'agit de la première campagne contre le duché franc du littoral, placé par Frédégaire * après le décès de Witteric » ce qui fait l'anné 610, combat poursuivi et achevé par Siscbut contre les Cantabres en 612, selon Frédegaire et aussi Isidore, ibidem $\$ 61$, p. 291. Julien de Tolede, " Historia Wambae *, anno 673, cd. B. Krusch, M.G.H. Scriptores Rerum Merowingicarum, \&. V, Hanovre, $1910 \mathrm{pp} 500 \mathrm{et} \mathrm{sq}$.

38. Frédégaire, op. el ed. cit. $\S 603 / 604, c$. 617/618. : * Eo anno Theudebentus et Theudericus exercitum contra Wascones dirigunt. ipsosque. Deo auxiliante. dejectos suae dominationi redigunt. et rributarios faciunt. Ducem super ipsos. nomine Geninlen instituunt, qui eos feliciter dominavit ».

39. Ibidem, $\$ 608 / 809$, c. $621 / 622$.

40. Ibidem, $\$ 633 / 634$, C. 642 . Voir la note 47 qui comprend le texte complet

41. Ibidem : * Eo anno, Palladius ejusque filius Sidocus, episcopus Aelosani. incusante Aighnnane duce. quod rebellionis Wasconorum fuissent conscii, exsilio retrudunsur ". Cette même anné, Palladius et son fils Sidoc évêque d'Eauze furent accusés par le duc Aeghyna d'être d'accord avec la rébellion des Wascones, ct ils furent condamnés à l'exil »

42. Fredegairc, "Chronique «, ed. cit. $\$ 632$, c. 641 , « rebellionis Wasconorum » et $\$ 648$, c. 654, « cum Wascones foriter rebellaren »

43. Edit de Clotaire II ed. A. Boretius, M.G.H., Legum Sectio, II. Capitularia Regum Francorum, l. I, Hanovre 1883, p. 23.

44. Frédégaire: op. et ed ; cil § 649, c. 654 : «... Aigyna ex genere Saxonum... m Il semble cependant que quelques Saxons aient tentê de s'enraciner dans la région. Grégoire de Tours cite le cas de $\propto$ Childéric le Saxon... réfugié dans la ville d'Auch où se trouvait une propriété de sa femme » op. et ed. cit. livre X, chapitre 22.

45. Concilium Clippiacensc, ed. F. Maassen, M.G.H.. Concilia, t. I. Concilia Aevi Merovingici, Hanovre 189.3. pp. 197 el 200.

46. Frédégaire, op. et ed ; cit. \$646, c. 652

47. ibidem, \$ 633/634. c.642. «Cumque regnum Chlotharii tam Neptrico quam Burgundiae a Dagoberto fuisset praeoccupatum, captis thesauris et suae ditioni redactis, tandem misericordia motus. consilio sapientium usus. citra Ligerem et limitem Spaniae, qui ponitur partibus Wasconiae, seu et montis Prrenaei pagos et civitates, quod fratri suo Chariberto ad transigendum ad instar privato habitu ad vivendum po. tuisset sufficere, noscitur concessisse : pagum tholosanum, catorcinum. agennensem, petrocoreum et sancionicuml, vel quod ab his versus montes Pyrenaeos excluditur, hoc tantum Charibento regendun concessit. quod et per pactionis vinculum strinxit. ut amplius Chariberus nullo tempore adversus Dagobertum de regno patris repetere praesumerel. Chariberlus sedem Tholosae eligens, regnat in parte provinciae Aquitanicae. Post annos tres postquam regnare coepisset. totam Wasconiam cum exercitu superans, suae ditioni redigit. aliquantulum largius fecit regni sui spatium ". "Comme Dagobert avait occups par avance ie royaume de Clotaire tant en Neustric qu'en Bourgogne, et qu'ayant pris ses tresors il les avait mis en sa possession. poussé cependant par la miséricorde ct selon le conseil des sages, il fait savoir qu'il concédait à son frère Chariber tout ce qui s'étend de la Loire au limès d'Espagne, dans les régions de la Wasconia, les comtés ct cités de la montagne pyrénéenne, et cela afin que, comme l'on fait en privé, il ait de quoi vivrc. Il donna en outre les comtés de Toulouse. Cahors, Agen, Périgueux et Saintes el ce qui s'étend de là aux monts Pyrénćes, à Charibert ct cela afin qu'il te gouvcrne. et il se l'attacha par un pacte selon lequel il renonçail à demander plus de l'héritage de son père. Charibert choisit Toulouse comme résidence el de là in règne sur unc parlic de la province d'Aquitanique. Trois ans après le début de son règne, tenant militairement la Wasconia tout entièrc. il la soumit en son pouvoir ce qui agrandit quelque peu le territoire de son royaume "

48. Ibidcm. $\$ 633$, c. $641 / 642$.

49. Ibidem. $\$ 635$, c. 64.3

50. Ibidem, voir la fin de la nolc 47

51. * Vita Sancti Amandi ". rédaction par son disciple Baudemund. ed. B. Krusch, M.G.H. Scriptores Rerum Merowingicanim, 1. V. Hanovrc 1910. p. 438.

52. Frédégairc. op. ct cd. cil ?. \$637. c. 647 . 
53. Ibidem. $\$ 641$ c. 648 . « Anno IX Dagoberti. Charibertus rex moritur, relinquens filium parulum nomine Chilpericum qui nec post moram defunctus est. Fertur factione Dagobeni fuisse interfectus. " « La neuvième annéc de règne de Dagobern (comme roi d'Austrasie avant le décès de son père), Charibert mourut laissant un jeune cnfant nomme Childéric qui ne lui survécut guère. On dit qu'il fut tué par la faction de Dagobert *.

54. G. Tessier, ed. Recueil des actes de Charles II le Chauve, Paris, 1955 acte $n^{\circ} 465$ pp. 536 à 545. le 21 Janvier 845 a Compiègne. Voir notre utilisation de cette charte, * La vicomté de Soule *, Le Pañs de Soule, ed. Ixpegi. Baïgorri, 1994.

55. Fréćgairc, op. ct ed. cit. \$641, c. 648 : * Omne regnum Charibeni, una cum Wasconia, Dagoberius protinus suae ditioni redigit. Thesauros quoque Chariberi Baronto duci adducendum et sibi praesenlandum direxil. Unde Baronius grave dispendium fecisse dignoscitur, una cum thesaurariis faciens, nimium exinde fraudulenter subtraxit. $*$ \& Dagobert réduisit aussitôt le royaume de Chariber, ainsi que la Wasconia en son pouvoir. Il ordonna au duc Baronte de lui apporter les trćsors de Chariber. Mais celui-ci fit, on le saik, une importante ponction, car agissant avec les tresoriers, il en enleva une grande part. *

56. Ibidem. \$ 649. c. 654. : Anno XIV regni Dagoberti. cum Wascones fortiter rebellarent et mullas praedas in regno Franconim quod Charibenus tenueral facerent.... ». * La XIV" année du règne de Dagobert. alors quc les Wascones se soulevaient avec force et commettaient de multiples dommages dans le royaume des Francs qu'avait tenu Charibert....

57. Ibidem, $\$ 650$, c.654/655.

58. Ibidem, \$ 649. c. 654 : «... In Wasconiam cum exercitu perrexissent et tola Wasconiae palria ab exercitu Burgundiae fitisset repleta. Wascones de inter montium rupibus egressi ad bellum properant... ". - Commc l'arméc parvenait en Wasconia et qu'elle occupait la totalité de la patrie Wasconia, les Wascones, sortant des montagnes, s'avancent pour le combat..... La tactique de guerre est par la suite completement exposćc. Les guerriers tendent un piège à l'assaillant, donnant l'impression d'un pays mal defendu et l'armée de Dagobert se déploie largement. Les hommes sont concentrés dans la montagne. Puis ils surgissent, le combat se déroule, et tournant le dos, les guerriers donnent l'impression de fuir. l'ennemi croit tenir la victoirc. mais les guerriers se dirigent de nouveau vers unc vallee, ici la Soule. En embuscade sur el dans les rochers, il fondent alors sur l'cnnemi qui les poursuit. Frédégaire a reçu ses informations de vive voix d'anciens de l'armée de Dagobert. avec une extrême précision.

59. Voir la note 61, in fine.

60. Pour les Goths : H. Wolfram. Histoire des Goths. Paris, 1990. Pour les Francs, P. Périn, Les Francs. 2 vol., Paris 1987.

61. Frédegairc op. et ed. cit.. \$ 651, c.655/656 : Anno XV regni Dagberni. Wascones omnes seniores terrae illius, cum Aigine duce, ad Dagobertum Clippiacum venerunt, ibique in ecclesia domni Dionysii regio timore perterriti confugium fecerunt. Clementia Dagoberti vilam habent indultan ; ibique sacramenis Wascones firmantes simul et promittentes se omni tempore Dagobeno et filiis suis regnoque Francorum fideles fore quod more solito. sicul saepe fecerant. posthac probavit eventus. Permissu Dagobeni Wascones

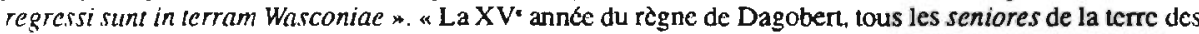
Wascones. ainsi que lc duc Acghyna, vinrent auprès de Dagober à Clichy. Remplis de crainte. ils cherchèrent refuge dans l'église de saint Denis. Ils eurent la vie sauve par la clémence de Dagober. Ils prêtèrent alors scrment ct en même temps promircnt d'être toujours fideles à Dagobert. à ses fils et au royaume des Francs. ce qui sc vérifia par la suite comme ils l'avaient toujours fait. Dagobert permil aux Wascones de renurer dans la terre de Wasconia. » 